\title{
OS CONDOMÍNIOS GREEN VILLAGE E GREEN WOODS E AS TRANSFORMAÇÕES NO ESPAÇO URBANO DE NATAL
}

\author{
Matheus Augusto Avelino Tavares \\ Graduado em Geografia pelo CEFET-RN e Mestrando em Geografia pela UFRN \\ matheusgeografo@yahoo.com.br
}

Maria Cristina Cavalcanti Araújo

Graduada em Licenciatura em Geografia -UFRN; Mestre e Doutoranda em Arquitetura e Urbanismo - UFRN; Professora do CEFET-RN

mariacristina@cefetrn.br

\begin{abstract}
RESUMO
O rápido crescimento urbano pelo qual o município de Natal passou nos últimos 20 anos fez emergir diversas formas de reconfiguração do espaço, dentre elas, as novas formas de morar, ou seja, os condomínios fechados horizontais. O presente estudo tem como objetivo discutir, inicialmente, a produção do espaço a partir dos condomínios fechados horizontais Green Village e Green Woods, analisando quais são as principais conseqüências que a construção desses empreendimentos trazem para a cidade. Para tanto, fizemos uma pesquisa que teve como base os procedimentos quantitativos, porém, que privilegiou os procedimentos de uma abordagem qualitativa. Os dados foram levantados a partir de duas fontes: na primeira foi feita uma pesquisa bibliográfica e documental sobre temas envolvendo os condomínios fechados, na segunda entrevistamos os moradores dos condomínios a fim de obter informações que nos revelassem quais foram os motivos que os levaram a escolherem tais empreendimentos como forma de moradia assim como, traçar um perfil socioeconômico desses grupos sociais. Os resultados obtidos foram analisados a luz de um arcabouço teórico. Para isso, fizemos uma reflexão sobre as diferentes formas de segregação presentes no espaço urbano, como e por que elas se desenvolvem e quais são os agentes sociais que produziram esta realidade. Dentro desta perspectiva, podemos dizer que os condomínios fechados horizontais engendram novas práticas socioespaciais que proporcionam a auto-segregação dos grupos sociais mais abastados e a formação de áreas que tendem a homogeneidade social.
\end{abstract}

Palavras-Chaves: Espaço Urbano, Condomínios Fechados, Auto-segregação.

\section{GREEN VILLAGE E GREEN WOODS RESIDENTIAL CONDOMINIUM AND URBAN TRANSFORMATIONS IN THE CITY OF NATAL}

\begin{abstract}
The fast urban growth for which Natal city it passed in last the 20 years made to emerge diverse forms of reconfiguration of the space, amongst them, the new forms to live, that is, the horizontal closed condominiums. The present study it has as objective to argue, initially, the production of the space from the horizontal closed condominiums of Green Village and Green Woods, analyzing which are the main consequences that the construction of these enterprises bring for the city. For in such a way, we made a research that had as base the quantitative procedures, however, that it privileged the procedures of a qualitative boarding. The data had been raised from two sources: in the first one a
\end{abstract}


bibliographical research and on subjects was made documentary involving the closed condominiums, in second interviews the inhabitants of the condominiums in order to get information that in disclosed which to them had been the reasons that had taken them to choose such enterprises as form of housing as well as, to trace a economic partner profile of these social groups. The gotten results had been analyzed through one it searches to a theoretical base. For this, we made a reflection on the different forms of present segregation in the urban space, as and because they develop themselves and which are the social agents who had produced this reality. Inside of this perspective, we can say that the horizontal condominiums closed produce new practical spatial partner that more provide the self segregation of the supplied social groups and the formation of sites that tend the social homogeneity.

Key-Words: Urban space, Closed Condominiums, Self-segregation. 


\section{OS CONDOMÍNIOS GREEN VILLAGE E GREEN WOODS E AS TRANSFORMAÇÕES NO ESPAÇO URBANO DE NATAL}

\section{INTRODUÇÃO}

A partir do final dos anos de 1980 e início dos anos de 1990 os condomínios fechados horizontais começaram a se difundir como opção de moradia para as classes de médio e alto poder aquisitivo da cidade de Natal. Deste modo, este trabalho tem como principal objetivo fazer uma análise dos condomínios Green Village e Green Woods a fim de desvendar quais são as práticas socioespaciais que estes empreendimentos engendram, bem como, entender quais são os principais motivos que levam as classes média e alta a procurarem este tipo de moradia.

A escolha dos condomínios Green Village e Green Woods como objeto de estudo se deu pelo fato desses empreendimentos serem os primeiros grandes condomínios fechados horizontais da cidade, se constituindo assim, num marco para a indústria imobiliária local.

Esta tipologia de moradia introduziu profundas transformações no tecido urbano da cidade, proporcionando a expansão e o parcelamento da terra urbana assim como, novos ideais de vida que tem como principal conseqüência à auto-segregação das populações de médio e alto poder aquisitivo.

A difusão dos condomínios fechados ou "enclaves fortificados” como opção de moradia está relacionada à propagação no seio da sociedade de uma cultura do medo por parte dos meios de comunicação. Dentro desse contexto, os agentes imobiliários usam a imagem de uma sociedade cada vez mais violenta para vender seus empreendimentos; outro motivo que não aparece implicitamente é a questão de se morar em um ambiente dedicado somente as classes de alto poder aquisitivo. Neste sentido, se busca uma vivência em espaços socialmente homogêneos que não são acessíveis para “qualquer um”.

O marco de referência teórica é orientado por temas e conceitos que visam compreensão de nosso objeto de estudo assim como, se destinará a responder algumas indagações que foram imprescindíveis como elementos norteadores do nosso trabalho, tais como; o que levou as classes média e alta a escolherem como local de moradia um condomínio fechado horizontal? Quais são as principais práticas socioespaciais engendradas por essas edificações?

Para o entendimento dessa problemática, buscou-se uma discussão teórica sobre os seguintes temas: espaço geográfico e os agentes sociais que o produzem, segregação socioespacial e os principais aspectos dos condomínios fechados horizontais, entre outros temas que serão abordados no estudo. Autores diversos, que se dedicam ao estudo da problemática urbana foram chamados para darem suas contribuições, tais como; Santos, Corrêa, Carlos, Villaça, Lefebvre, Caldeira, dentre outros.

\section{PRODUÇÃO E USOS DO ESPAÇO URBANO}

A cada momento da história temos uma definição diferente do espaço, isto ocorre porque o mesmo é dotado de uma constante dinamicidade e está em permanente estado de transformação e construção. Dessa forma, torna-se tarefa difícil sua definição, que, 
conforme pontua Santos (2004, p.151) "é árdua, porque a sua tendência é mudar com o processo histórico, uma vez que o espaço geográfico é também o espaço social”. Portanto, não podemos definir o espaço como algo que é imutável ou dissociado do homem. Neste sentido uma definição nos é dada por Carlos (1994, p. 33-34); onde

O espaço geográfico não é à base da história mundial, mas produto das relações fundamentadas na divisão do trabalho que ocorrem num determinado momento histórico entre os homens e a natureza. É um processo de produção e também é um de reprodução, fundamentado de um lado na acumulação técnico-cultural, e, de outro, na relação dialética entre o velho e o novo (o processo de produção atual em si), implicando a idéia de continuidade - do processo de desenvolvimento histórico.

Assim, podemos dizer que o espaço geográfico é o resultado da interação e das transformações produzidas pelo trabalho social sobre o meio natural ao longo dos períodos históricos e que ele só se constitui como tal mediante a presença do homem que é quem o produz e (re)produz permanentemente.

Destarte, o processo de produção do espaço ocorre de forma diferenciada, quer dizer, ele é fruto de ações articuladas e contraditórias desenvolvidas por diversos agentes sociais. Estes, por sua vez, atuam na produção da cidade seguindo uma lógica própria, como muito bem nos relata Calixto (2004, p. 46) “[a] atuação [dos agentes] pode ser marcada pela convergência ou divergência de interesses, refletindo, mediante suas intervenções, relações políticas de alianças ou de conflitos entre os diferentes segmentos sociais”. Diante disto, cabe aqui expor quais são os agentes que atuam diretamente na produção do espaço e qual o papel que cada um deles desempenha dentro do processo de construção da cidade.

\subsection{Os agentes produtores dos condomínios horizontais}

Muitos são os autores que discutem a respeito de quem e quais são os agentes que produzem (re)produzem o espaço urbano. Corrêa (2003) aponta que, os proprietários dos meios de produção, sobretudo as grandes indústrias, os proprietários fundiários, os promotores imobiliários, o Estado e os grupos sociais excluídos são os agentes sociais que fazem e (re)fazem a cidade. Ribeiro (1997) nos diz que; o incorporador, o construtor, as instituições de crédito imobiliário e os proprietários rentistas são os agentes responsáveis pela produção e circulação de moradias no espaço urbano e Costa (2000) nos diz que: os proprietários de terras e de imóveis, as incorporadoras de imóveis, as construtoras de imóveis, as corretoras de imóveis, as instituições financeiras, as intuições públicas e os moradores são os agentes que atuam no processo de produção do espaço urbano.

Como se pode perceber eles discutem sobre os mesmos agentes produtores do espaço urbano, entretanto, usam uma nomenclatura diferente. Neste trabalho nos deteremos mais especificamente, no capital imobiliário, no Estado e nos grupos sociais.

Todos esses agentes atuam de forma inexorável no processo de transformação do espaço urbano, cada qual o faz segundo os seus próprios interesses, entretanto, é preciso entender que a atuação de um determinado agente em uma parcela do espaço não ocorre de maneira isolada, ou seja, ela não excluí a ação dos demais agentes no processo de produção da cidade. Assim, é preciso saber qual é o papel que cada um dos agentes sociais desempenha no processo de (re)produção e de modelação do espaço, sendo também de fundamental importância entender que todo esse processo ocorre em meio a um jogo de conflitos e de interesses particulares, questões que serão analisadas a seguir. 
Por capital imobiliário entendemos um conjunto de agentes que juntos e articulados exercem papel fundamental na produção dos condomínios horizontais e, por conseqüência, no processo de produção do espaço urbano, são eles: o incorporador, o construtor e as corretoras de imóveis.

O incorporador é peça fundamental para o capital imobiliário, ele é o agente que incorpora e quem na realidade cria o empreendimento, segundo Souza (1994, p. 192) "o incorporador é o que desmembra o terreno em ‘frações ideais'; portanto, é quem cria o solo”.

Desse modo, é a partir da atuação dos incorporadores que teremos a transformação do capital-dinhero em imóvel, são eles que obtêm financiamento para a compra dos terrenos e venda dos imóveis, assim como, quem decide o local da construção, as dimensões das unidades e o tipo de material que será usado. Ribeiro (1997, p. 96) aponta que o incorporador é "a chave de todo o processo de produção e circulação, na medida em que permite a transformação de um capital-dinheiro em terreno e edificação”. Ainda é importante destacarmos que o incorporador pode exercer diversas funções em uma dada situação. Com isso, ele pode ser, ao mesmo tempo, incorporador, construtor, agente fundiário, ou seja, não há uma definição estratégica para a atuação desse agente.

O construtor é quem realiza a produção física do imóvel segundo os padrões técnicos, arquitetônicos e comerciais pré-estabelecidos pela figura do incorporador. O processo de produção dos imóveis é dividido em diversas etapas, podendo assim, contar com a participação de diversas empresas, que vão desde firmas de grande porte, aquelas que ficam responsáveis por quase todo o processo, até pequenas construtoras que se especializam em uma etapa do processo, como por exemplo, a terraplanagem a concretagem, etc.

No caso da produção dos condomínios horizontais, o construtor que está diretamente ligado ao incorporado não é o responsável pela construção dos imóveis, isto porque neste tipo de empreendimento são os moradores os responsáveis pela construção das residenciais, o que dessa forma pode ocorrer com firmas diversas; o construtor é somente responsável por melhorar as condições de construtibilidade do terreno e por implantar todo o aparato de infra-estrutura básica que o empreendimento exige.

As corretoras de imóveis também fazem parte do capital imobiliário. Estes agentes são os responsáveis pela coordenação do mercado de imóveis, segundo concorrência que estabelecem entre si. De acordo com Harvey (1980, p. 140), "operam no mercado de moradia para obter valor de troca. Eles obtêm lucro através de compra e venda ou através de cobrança de custos de transação para seus serviços como intermediários”, ou seja, as corretoras também são responsáveis pela comercialização do produto-mercadoria, tendo em vista que atuam como um elo de intermediação na negociação entre as incorporadoras e o comprador do imóvel.

No mercado de moradia, e no que diz respeito aos condomínios horizontais, as corretoras são, muitas vezes, responsáveis por promoverem o marketing do empreendimento, criam no seio da sociedade novos ideais, ou como dizem "novos conceitos de moradia”. Além disto, "desempenham uma grande influência na determinação do consumo, sugerindo, criando necessidades, apresentando opções aos agentes que adquirem os imóveis e induzindo-os a uma determinada escolha” (COSTA, 2000, p. 50). 
O Estado, por sua vez, também desempenha importante papel no processo de produção do espaço urbano, sua atuação se manifesta de diversas formas. Primeiramente, ele pode atuar estabelecendo normas ou leis que devem, pelo menos teoricamente, disciplinar o uso e ocupação do solo urbano como, por exemplo, os planos diretores que dependendo do jogo de interesses pode restringir ou ampliar a produção do espaço urbano. Sua atuação também pode ocorrer através de medidas de caráter tributário, isto é, o Estado exerce o papel de cobrador de taxas e impostos de bens ou de serviços públicos. Além disto, sendo também alvo de reinvidicações por obras e serviços públicos por parte dos diferentes agentes sociais, o Estado, exerce o papel mediador dos conflitos sociais que emergem no espaço urbano.

A atuação do Estado também se expressa por meio de políticas de inversões financeiras para a implantação de obras e serviços destinados a sociedade. Dentro desse contexto a sua atuação concorre, muitas vezes, para uma valorização diferenciada no interior das cidades e para a determinação de seu crescimento, pois,

sempre que o poder público dota uma zona qualquer da cidade de um serviço público; água encanada, escola pública ou linha de ônibus, por exemplo, ele desvia para esta zona demandas de empresas e moradores que, anteriormente, devido à falta do serviço em questão, davam preferência a outras localizações. Estas novas demandas, deve-se supor, estão preparadas a pagar pelo uso do solo, em termos de compra ou aluguel, um preço maior do que as demandas que se dirigiam à mesma zona quando esta ainda não dispunha do serviço. Daí a valorização do solo nesta zona, em relação ás demais. (SINGER, 1979, p. 34).

Desse modo, a atuação do Estado realmente se concretiza na construção de obras e serviços destinados teoricamente a todos os setores da sociedade, (pavimentação, saneamento básico, iluminação, escolas, postos de saúde). Entretanto, esses serviços de consumo coletivo não ocorrem de forma homogênea no espaço, o que percebemos é que essas obras muitas vezes privilegiam uma pequena parcela da sociedade que já ocupam posições favorecidas na distribuição de renda social. Dessa forma, aumenta-se ainda mais a discrepância existente entre as classes sociais, uma vez que, serviços que deveriam atender de forma homogênea a todos os segmentos acabam privilegiando apenas alguns setores sociais.

Assim, por meio dos investimentos em obras e serviços públicos o Estado, em uma sociedade capitalista, pode muitas vezes agir visando, principalmente, criar mecanismos para incrementar o processo de reprodução do capital, pois com essas inversões “é potencializada a percepção da renda fundiária por parte dos agentes privados, sendo, em outras palavras apropriada de forma privada uma parte do excedente social, desviado de sua realização sob a forma de lucro" (Low-Beer, 1983, 37), diante disto, entendemos que muitas das ações do Estado beneficiarão principalmente a pequenos, porém, privilegiados grupos sociais.

Por fim, temos os grupos sociais que dentro de qualquer sociedade exercem importante papel no processo de produção do espaço. Para esses agentes a habitação é consumida com vistas a suprir diferentes interesses e desejos que se relacionam diretamente à posição em que se encontram dentro do processo de distribuição da renda produzida socialmente.

Para este grupo a moradia está, fundamentalmente, revestida de um valor de uso, embora nela também esteja embutido um valor de troca, pois muitas vezes os grupos sociais, 
independente da classe que ocupam, pensam na moradia como promotores imobiliários. Para Harvey (1980, p. 140) o valor de uso da moradia é determinado "pela consideração conjunta de uma situação pessoal ou de família e uma casa particular em uma localização particular. Os usuários proprietários estão relacionados com os valores de uso e agem de acordo com isso".

É de suma importância destacar que não há como delimitar de maneira precisa o papel que cada um desses agentes exerce na produção do espaço urbano, principalmente, pelo fato de que um agente pode assumir o papel de outros e vice-versa, ou ainda, porque eles podem "agregar-se ou desagregar-se, neste ou naquele empreendimento, assumindo, portanto, papéis e figuras jurídicas que variam com o tempo” (SOUZA, 1994, p. 189).

Destarte, a atuação de todos esses agentes sociais nos leva a um quadro de grande complexidade, isto porque estes operam no processo de construção da cidade segundo anseios e necessidades próprios a cada grupo, o que, por conseqüência, leva a práticas que produzem de modo descontínuo e diferenciado o espaço urbano. È dentro desse contexto de mudanças e transformações que analisaremos a produção do espaço a partir dos condomínios fechados horizontais Green Village e Green Woods.

\section{UMA REFLEXÃO SOBRE A SEGREGAÇÃO SOCIOESPACIAL}

São muitas as discussões que envolvem o conceito de segregação, uma vez que ao longo dos anos esta problemática serviu de objeto de estudo para inúmeros teóricos. Por exemplo, para Lefebvre, em sua obra "A Revolução Urbana”, há uma distinção entre os conceitos de diferenciação de um lado e segregação e separação do outro. O autor nos mostra que: "a separação e a segregação rompem a relação. Constituem, por si sós, uma ordem totalitária, que tem por objetivo estratégico quebrar a totalidade concreta, espedaçar o urbano. A segregação complica e destrói a complexidade” (LEFEBVRE, 2004, p. 124).

Já o processo de diferenciação que emerge dentro do espaço urbano permite o intercâmbio, a troca de experiências e de informações entre os grupos sociais. Sendo assim, a segregação é produto final de um processo de separação ou apartação que conduz os grupos urbanos a formarem núcleos que apresentam forte homogeneidade entre si e grande disparidade perante os demais, este processo acaba por romper com o intercâmbio entre os grupos sociais, provocando assim a fragmentação social do tecido urbano (LEFEBVRE, 2004).

Nesta mesma linha de raciocínio Castells (1983, p. 210) nos mostra que a segregação dentro do espaço urbano se dá a partir da formação no espaço de "zonas de forte homogeneidade social interna e de forte disparidade social entre elas, entendendo-se essa disparidade não só em termos de diferença como também de hierarquia”. Como podemos perceber, o autor entende a segregação como um processo que tende a concentrar os grupos sociais em determinadas parcelas do espaço urbano, formando assim, zonas que apresentam características internas semelhantes e grandes disparidades com relação às demais zonas da cidade.

Por sua vez, Villaça (1998, p.142) entende segregação como “um processo segundo o qual diferentes classes ou camadas sociais tendem a se concentrar cada vez mais em diferentes regiões gerais ou conjunto de bairros da metrópole”. Um ponto importante dentro da 
análise que o autor faz sobre a segregação é que não há exclusividade das camadas de alta renda em nenhuma região das metrópoles brasileiras, e mesmo nos bairros que tendem a uma grande concentração de uma mesma classe, não há como impedir a presença ou o desenvolvimento de outras classes dentro do mesmo espaço urbano.

Villaça assinala que existem as mais variadas naturezas de segregação espacial nas cidades brasileiras (de classes, etnias, ou nacionalidades), sendo, a segregação espacial dos bairros residenciais por classes sociais uma das mais presentes em nossas cidades. Todavia, isto não quer dizer que exista mais de um tipo de segregação dentro do espaço urbano, pois a segregação "é um processo dialético, em que a segregação de uns provoca, ao mesmo tempo e pelo mesmo processo, a segregação dos outros (VILLAÇA, 1998, p. 148)”.

Para Corrêa (2003), a segregação é um processo que tem sua origem com o advento das classes sociais, não sendo esta exclusividade da sociedade capitalista. A segregação residencial seria a projeção no espaço das classes sociais existentes no sistema capitalista, sendo fruto dos agentes sociais (o Estado, os Promotores Imobiliários e os Incorporadores imobiliários) que atuam no processo de produção do espaço urbano.

Corrêa (2003) fala ainda da existência de uma auto-segregação das populações mais abastadas, como também de uma segregação dos segmentos mais pobres da sociedade, esta é entendida como sendo imposta. Neste mesmo sentido, Sogame (2001, p. 100) nos diz que, atualmente "pode-se dizer que existe tanto uma segregação espacial da população pobre como uma auto-segregação da população rica”.

Dentro dessa análise, os grandes condomínios fechados horizontais localizados na periferia das cidades podem ser considerados um exemplo claro de auto-segregação das populações das classes média e alta, na medida em que é uma atitude de isolamento intencional. Essas classes mais abastadas se retraem voluntariamente em suas residências delimitando assim um espaço exclusivo para o lazer, o consumo e o trabalho (SOGAME, 2001).

Assim, podemos dizer que a segregação espacial se constitui em um complexo processo de produção e consumo diferenciado de espaço. Este processo tem como principal objetivo à formação e a divisão do espaço em áreas sociais que tendem a apresentar fortes características estruturais (acesso aos meios de consumo coletivo), culturais, ideológicas, políticas e econômicas homogêneas internamente, apresentando, as mesmas, grandes disparidade em relação às demais áreas.

\subsection{Espaços de auto-segregação: condomínios fechados horizontais}

O primeiro condomínio fechado horizontal implantado no Brasil no início da década de 1970 no Estado de São Paulo foi o Alphaville. Este empreendimento à época de seu lançamento revolucionou o mercado imobiliário nacional proporcionando uma nova forma de moradia para as classes média e alta.

Tal empreendimento foi inspirado nos subúrbios norte-americanos e trouxe uma nova forma de moradia para a sociedade brasileira, que de certa maneira, se baseou nos ideais de residências unifamiliares com grandes áreas verdes e segurança privada etc. (CALDEIRA, 2000).

Embora tenha como inspiração os common interest developments ou incorporações de interesses comuns (CIDs), os condomínios fechados lançados no Brasil possuem algumas 
diferenças dos originais americanos, uma delas é que as casas são construídas comumente pelos próprios proprietários, diferente do que ocorre nos Estados Unidos, onde é o incorporador o responsável pela construção dos imóveis. Tal diferença faz com que os condomínios fechados brasileiros não possuam um desenho uniforme, ou seja, as casas não são padronizadas e possuem uma arquitetura individualizada, entretanto, há que se respeitar os parâmetros de edificação estabelecidos por cada condomínio (CALDEIRA, 2000).

Uma outra diferença é que os condomínios fechados do Brasil são via de regra murados e têm a entrada de pessoas controlada, já na matriz americana este tipo de empreendimento fechado (gated communities) só responde a aproximadamente $20 \%$ dos CIDs (CALDEIRA, 2000). Os empreendimentos fechados dos Estados Unidos são chamados geralmente de comunidades, ou seja, é ressaltado o valor de se ter à possibilidade de fazer tudo em conjunto. No Brasil os condomínios nunca são chamados de comunidades, isto seja talvez por que aqui a idéia de comunidade é sempre designada para as áreas pobres como, por exemplo, os cortiços ou as favelas. Logo "os moradores brasileiros parecem desprezar bastante essa idéia de comunidade” (CALDEIRA, 2000, p. 262).

Tal tipologia de moradia, que surge no Brasil no auge da produção imobiliária, explorou bastante a idéia de novas formas de habitat que contam com ampla segurança. Neste sentido, os grupos sociais mais abastados, influenciados pela mídia e com medo da violência crescente da grande cidade, passam a fugir dos espaços públicos e vão se refugiar em grandes condomínios fechados, mudando assim, significativamente, a dinâmica das cidades e das relações entre as diferentes classes sociais. Caldeira (2000, p. 258), nos diz que os condomínios fechados são:

A versão residencial de uma categoria mais ampla de novos
empreendimentos urbanos que chamo de enclaves fortificados. Eles
estão mudando consideravelmente a maneira como as pessoas das
classes média e alta vivem, consomem, trabalham e gastam seu tempo
de lazer. Eles estão mudando o panorama da cidade, seu padrão de
segregação espacial e o caráter do espaço público e das interações
públicas entre as classes.

Sposito (1999, p. 90) nos diz que os condomínios fechados fazem parte das novas "formas de habitat urbano foram e são apresentadas como paraísos habitacionais, uma espécie de neo-village, nas quais se pode viver, ao mesmo tempo, fora e dentro das grandes áreas urbanas”.

Estas edificações possuem as características de se localizarem em grandes áreas na periferia das grandes cidades, terem um elevado número de residências, apresentarem áreas de lazer exclusivas (com playgrouds, piscinas, quadra de tênis, campo de futebol etc.) possuir grandes espaços verdes, centro de comércio e ainda são rodeadas ou "protegidas" por grandes muros.

Dentro deste enfoque, percebemos que o surgimento dessas edificações está de certa forma, atrelado ao aumento da violência urbana, dos seqüestros, dos assaltos, e de toda a variedade de crimes produzidos pelas grandes cidades. Também não podemos esquecer que aliado a esse fator temos o grande marketing e o discurso sensacionalista dos agentes imobiliários que através de comerciais difundem a idéia de se morar em grandes casas 
cercadas com áreas verdes e que ainda são protegidas contra a violência urbana, como se elas fossem verdadeiras fortalezas imunes à ação dos criminosos.

Também é verdade que, agregado a todos esses fatores anteriormente mencionados, temos a questão do prestígio de se morar em condomínios residenciais que se destinam principalmente às populações de alta renda; neste sentido, a moradia passa a ser entendida como uma questão de status ou de ascensão social, ou seja, para alguns segmentos a moradia "coloca-se como um problema de prestígio e status, e os lançamentos imobiliários e as campanhas publicitárias ajudam a criar imagens para determinados bairros; alguns ‘viram moda' e passam a ser símbolo de prestígio social”' (Carlos, 1994, p. 161).

Sendo assim, os condomínios fechados horizontais viraram moda e, a partir do final dos anos 1980 e início dos anos 1990, começam a se difundir por todo o Brasil. Em Natal, segundo Souza e Silva (2004) o primeiro condomínio fechado horizontal foi o Vila Rica, construído em 1989 e localizando-se na rua Romualdo Galvão. Entretanto, é importante destacar que este condomínio não se enquadra nos padrões anteriormente mencionados, ou seja, ele não se encontra na periferia da cidade, apresenta um número reduzido de residenciais (12 no total), não dispõem de áreas de lazer privativas e ainda não possuem espaços verdes para o lazer de seus moradores. Neste sentido, podemos afirmar que os condomínios Green Village e Green Woods são os primeiros grandes empreendimentos da cidade.

\section{UMA RADIOGRAFIA DOS CONDOMÍNIOS GREEN VILLAGE E GREEN WOODS: DESVENDANDO OS MORADORES E SUAS FORMAS DE MORAR}

O condomínio Green Village, construído pela construtora FBF Empreendimentos Ltda., foi o primeiro grande empreendimento fechado horizontal produzido pela indústria imobiliária de Natal, inserindo assim uma nova tipologia de habitat urbano direcionada principalmente para os grupos sociais da classe média e alta. Este padrão de habitat fechado introduz novas formas de produção socioespaciais que tem como principal repercussão o surgimento de áreas de auto-segregação.

Este tópico tem como principal objetivo traçar um perfil socioeconômico dos moradores dos condomínios em questão, assim como, desvendar porque esses grupos sociais escolheram esse padrão de habitat como local para viverem.

A pesquisa de campo demonstra que as famílias do condomínio Green Village se situam em uma posição privilegiada dentro da sociedade natalense, estando inseridas nas classes média e alta. Como podemos observar a faixa de rendimentos mensais que aparece com mais freqüência corresponde a mais de 30 salários mínimos, o que corresponde a 57\% de seus moradores. A segunda classe de rendimentos que aparece com mais freqüência situase entre 26 e 30 salários mínimos, correspondendo a $29 \%$ dos moradores. Há apenas uma pequena parcela de famílias que tem rendimentos em torno de 11 e 15 salários mínimos. Este fato é explicado por que quando de seu lançamento, o empreendimento por seu caráter inovador, teve dificuldades para ser comercializado inicialmente, o que acabou forçando os seus empreendedores a reduzirem os preços para possibilitarem assim, o acesso a camadas sociais com um poder aquisitivo mais baixo (SOUZA e SILVA, 2004). 
Estes números demonstram que essas edificações são voltadas especialmente para um público seleto de pessoas, ou seja, elas atendem, principalmente, a famílias que tem um alto poder aquisitivo e que são vistas como sendo a elite da cidade, conforme nos é relatado pelo empreendedor imobiliário da construtora FBF empreendimentos quando este descreve: "os compradores do condomínio Green Village como "classe A", com idade entre 40 e 50 anos, a maioria de natalenses que já residia confortavelmente em imóveis próprios localizados em outros bairros nobres da cidade” (SOUZA e SILVA, 2004, p. 235).

No condomínio de Green Woods, que também foi construído pela FBF Empreendimentos Ltda., o patamar que aparece com mais freqüência corresponde à faixa de mais de 30 salários mínimos, Perfazendo 40 \% de suas famílias. A segunda faixa de renda de maior freqüência situa-se entre 16 e 20 salários mínimos seguida pelas famílias que tem rendas entre 21 e 25 salários mínimos, estas duas faixas somam juntas 50\% das famílias do condomínio.

Há ainda uma pequena parcela que tem ganhos mensais entre 5 e 10 salários mínimos, tal realidade está um pouco fora dos padrões do condomínio, isto talvez seja explicado pelo fato deste empreendimento a época de seu lançamento ter sido direcionado para um público com o poder aquisitivo mais baixo, conforme nos mostra Souza e Silva (2004, p.168) “o projeto deste condomínio é semelhante ao do Condomínio Green Village, tendo como diferencial básico ser um empreendimento para uma faixa de renda um pouco mais baixa. Assim, reduziu-se dimensões dos lotes, vias e das áreas verdes como forma de baratear o custo final”.

Cruzando os dados do condomínio Green Woods com os do Green Village percebemos que este último apresenta uma população com rendimentos mensais um pouco superiores ao primeiro; enquanto no Green Woods a parcela de famílias que tem renda mensal acima de 30 salários mínimos é de $40 \%$, no Green Village este percentual gira em torno de 60\%. No Green Woods a maior parte das famílias apresenta rendimentos entre 16 e 25 salários mínimos; já no Green Village mais de $85 \%$ de seus moradores têm ganhos mensais superiores a 26 salários mínimos.

A introdução pelo mercado imobiliário dos condomínios fechados ou "enclaves fortificados" como forma de moradia, mudou significativamente o padrão de relações sociais entre as diferentes classes sociais; neste sentido, temos as classes sociais de alto poder aquisitivo se refugiando em suas residências como se elas fossem verdadeiras fortalezas. É tentando desvendar o que levou esses grupos sociais a escolherem tais edificações como locais de moradia que analisaremos os próximos itens.

Quando indagados sobre quais foram os motivos que os levaram a morar em um condomínio fechado, a resposta mais freqüente é a questão da segurança. Outros aspectos podem até ser citados como, por exemplo, tranqüilidade, espaço, casa própria etc., mas a segurança é o fator determinante parar a escolha de um condomínio fechado como local de residência. Caldeira (2000) nos diz que os moradores dos condomínios fechados acham positivo o fato de serem rodeados por grandes muros com cercas elétricas, câmeras que os vigiam 24 horas por dia, guardas que patrulham o condomínio etc.

Esta realidade acima descrita é também encontrada nos condomínios de Green Village e Green Woods, por exemplo, quando perguntados sobre quais foram os motivos que os 
levaram a residir em um condomínio fechado, a resposta mais freqüente é a questão da segurança, com $70 \%$ das opiniões dos condôminos. Casa própria, tranqüilidade e espaço também foram citados pelos moradores. No entanto, a segurança sempre é o ponto determinante para a maioria deles, este aspecto aparece implicitamente na fala de uma moradora do Green Village quando esta diz que "nas ruas do nosso condomínio horizontal, meus filhos podem passear de bicicleta tranquilamente, fato que, se morássemos em outro lugar, isso jamais aconteceria” (ESTILO NATAL SHOPPING, 2006, p. 27).

A fala da moradora está em perfeita sintonia com a realidade vigente no condomínio, aí a arquitetura defensiva se faz amplamente presente. Por exemplo, o condomínio tem sua entrada controlada 24 horas pelos porteiros (figura 1), possui vigilantes que percorrem todas as vias internas, é rodeado por um muro de cerca de 4 metros de altura com cerca elétrica e apresenta ainda, guarita em diversos pontos específicos.
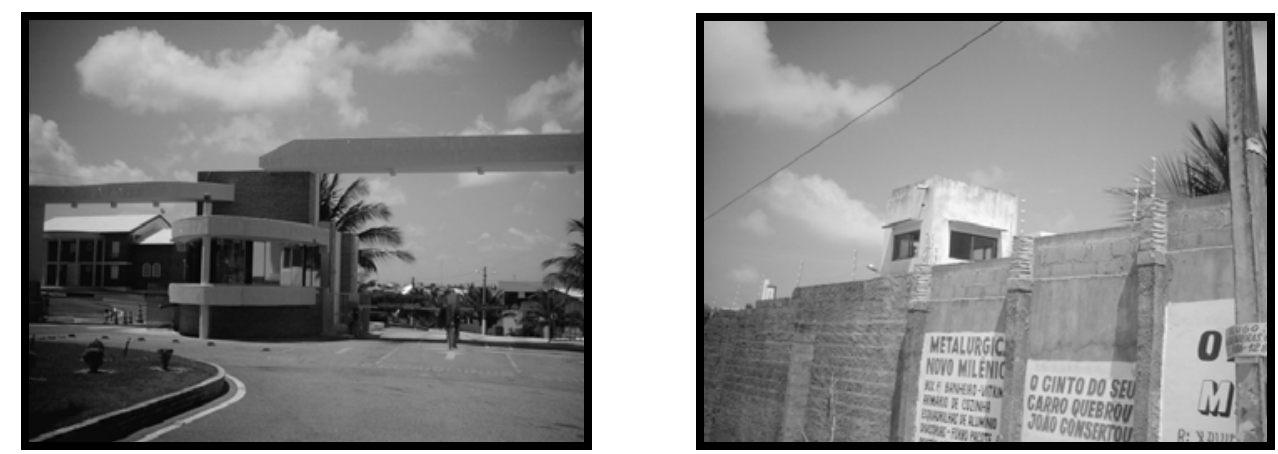

Figura 1 - Guarita na entrada e nos fundos do Green Village.

Fonte: Matheus Tavares (2006).

Quando analisamos os dados dos condomínios em separados, percebemos que eles fazem parte de uma mesma realidade. No Green Village, 72\% dos moradores responderam que o fator segurança foi o ponto determinante para a escolha da moradia, ainda foram citados: tranqüilidade e casa própria com $14 \%$ cada.

No Green Woods os números são bastante semelhantes, por exemplo, 65\% dos moradores atribuem à segurança como o fator determinante para a escolha da moradia e em segundo lugar vem tranqüilidade com $21 \%$, sendo que este último estar de certa forma ligado à segurança, outros fatores são também mencionados, como espaço e casa própria perfazendo $7 \%$ cada.

Conforme foi mencionado anteriormente, a questão da segurança foi o principal motivo que levou esses grupos sociais a escolherem um condomínio fechado como local de residência, mas, cabe aqui destacar que quando do lançamento dos empreendimentos em 1995, ou seja, há onze anos atrás a violência urbana ainda não se destacava como um dos principais problemas da cidade, portanto, não havia justificativa para a produção desses empreendimentos. 


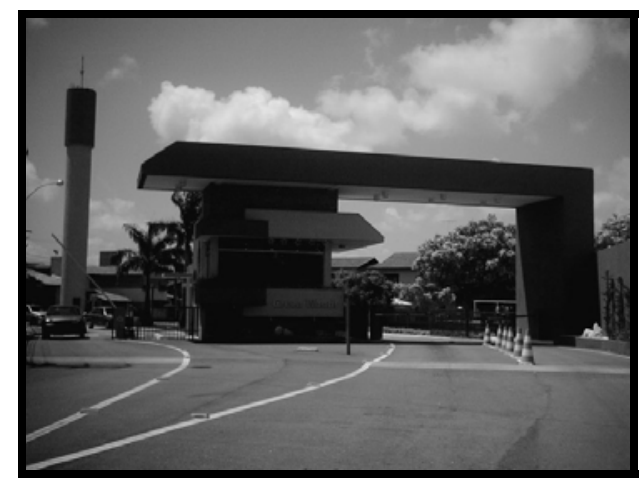

Figura 2 - Guarita de entrada no Green Woods.

Fonte: Matheus Tavares (2006).

Ainda no que toca a questão da segurança, a arquitetura defensiva existente em ambos os condomínios é vista pelos seus habitantes como sendo algo útil à segurança interna, neste sentido, os moradores dos condomínios se sentem amplamente protegidos quando estão em suas residências.

A sensação de segurança dentro dos condomínios aparece refletida na pesquisa de campo, por exemplo, no Green Village 86\% dos moradores responderam que sempre sentem a sensação de que estão seguros dentro do condomínio, somente $14 \%$ responderam que às vezes se sentem seguros; no Green Woods $90 \%$ dos condôminos nos disseram que sempre se sentem seguros, apenas $10 \%$ mencionaram que às vezes se sentem seguros. Cabe ainda destacar que em nenhum dos condomínios houve a resposta de que raramente se sentem seguros.

Quando perguntados sobre o que acham dos altos muros que rodeiam o condomínio, 90\% dos moradores do Green Woods responderam que estes passam à sensação de proteção, outros $10 \%$ responderam que eles transmitem a sensação de conforto. Parece realmente que os moradores do condomínio não se incomodam nenhum pouco com a altura de seus muros e tendem a ver o enclausuramento como sendo algo positivo.

Em relação ao condomínio Green Village, verificou-se que o fator proteção também aparece como sendo a principal sensação em relação aos muros altos com $72 \%$ das opiniões, porém, essa porcentagem aparece em menor proporção quando comparamos ao Green Woods. Os imensos muros que rodeiam o condomínio ainda transmitem a sensação de conforto para $14 \%$ dos moradores. O que merece atenção no Green Village é o fato de que outros $14 \%$ de seus moradores terem respondido que os altos muros transmitem a sensação de desconforto.

Esta realidade se assemelha àquela narrada por Caldeira (2000) quando esta diz que algumas pessoas sentem que suas residências se transformaram em verdadeiras prisões e vêem de maneira negativa o fato de suas casas estarem cercadas por muros, cercas eletrificadas e outros aparatos de segurança, enfim elas se sentem desconfortáveis.

Conforme foi mencionada anteriormente a questão da segurança é realmente o ponto que mais atrai moradores para os condomínios fechados, este fato nos é relatado por Souza e Silva (2004, p. 227) quando esta analisa a realidade do Green Woods; 
A segurança se constitui um dos fatores mais importantes para os moradores dos condomínios estudados, o que justifica o aumento de taxas condominiais e melhoramentos freqüentes na sua estrutura física. Segundo o administrador do Green Woods, os interessados em comprar imóveis neste condomínio procuram primeiro saber sobre o regime de portaria, número de seguranças e o tipo de equipamento disponível.

Sabendo disso a indústria imobiliária explorará bastante a questão da segurança e difundirá através de seus anúncios a idéia de que os condomínios fechados são locais ideais para se fugir não só da violência urbana, mas também do trânsito, da poluição e da correria diária, ou seja, o local ideal para se ter uma melhor qualidade de vida. Eles nos dão à nítida impressão de que a solução de todos os problemas urbanos está dentro de um condomínio fechado.

Outro tema que serve de parâmetro para analisarmos a realidade dos condomínios fechados horizontais é a questão das vantagens e desvantagens que os moradores sentem em relação à moradia nestes espaços. Observem que novamente a segurança é o item apontado como de maior vantagem em morar no condomínio.

A segurança aparece citada por 37\% dos moradores do Green Village como a principal vantagem do condomínio. O item conforto é citado por $25 \%$ dos moradores, outros $25 \%$ dizem que a boa localização também se constitui em uma boa vantagem que a moradia concede, por fim $13 \%$ mencionam a qualidade de vida como uma boa vantagem do condomínio.

No que diz respeito às desvantagens é preciso citar que os moradores do Green Village não mencionam em nenhum momento a questão do isolamento ou enclausuramento como sendo um ponto negativo do condomínio, porém, quando perguntados sobre a sensação que os muros dos condomínios causavam, uma parcela de moradores afirmou que se sentem desconfortáveis.

Com base pesquisa de campo, percebemos que $60 \%$ dos entrevistados afirmam não existir nenhuma desvantagem na moradia, e, o único ponto que aparece é o fato de o condomínio se encontrar um pouco distante das praias. Parece que os moradores do Green Village já se acostumaram com a possibilidade de encontrarem quase tudo o que precisam dentro do condomínio e vêem como única desvantagem do empreendimento o fato de que as praias se encontram um pouco distantes de suas residências, este fato termina por ser um pouco contraditório uma vez que os mesmo afirmam que a forma de lazer também está restrita á área do condomínio.

Já no Condomínio de Green Woods por sua vez, não apresentou resultados diferentes, novamente a questão da segurança se destaca, sendo apresentada como a principal vantagem da moradia no condomínio. A questão da segurança é mencionada por $42 \%$ dos moradores como sendo a principal vantagem que o condomínio oferece, também é citado como sendo uma outra vantagem o item conforto, que foi referenciado por $29 \%$ dos moradores, outros 29\% mencionaram a qualidade de vida como um aspecto importante do Green Woods. 
No que diz respeito às desvantagens, a maioria dos moradores mencionaram não encontrarem nenhum problema no condomínio, reforçando a idéia que os condomínios fechados isolam os moradores dos problemas que são comuns da vida urbana. Somente $20 \%$ dos entrevistados nos disseram que a única dificuldade encontrada no condomínio diz respeito à falta de transporte coletivo para o deslocamento dos funcionários, entretanto, este seria um problema que não diz respeito à administração do condomínio e sim aos órgãos públicos. É importante frisar que este mesmo problema também é sentido pelos funcionários do Green Village, no entanto, isto não foi mencionado em nenhum momento pelos seus moradores. Assim, diferentemente do Green Village, os moradores do Green Woods se mostraram um pouco mais preocupados com a situação dos seus trabalhadores.

Os anúncios publicitários além do fator segurança ressaltam também que nos condomínios fechados horizontais os seus moradores podem desfrutar de amplas áreas de lazer como piscinas, quadras de esportes, academias, sauna, play ground, praças, salão de festas, jogos etc. Os próximos tópicos analisam com que freqüência esses serviços são utilizados pelos condôminos.

Verificou-se no condomínio de Green Woods que 70\% dos moradores responderam que às vezes utilizam as áreas de lazer, outros $20 \%$ responderam que nunca usam as áreas de lazer e somente $10 \%$ mencionaram que as utilizam sempre. No Green Village, os dados da pesquisa nos dizem que $57 \%$ dos moradores nunca utilizam as áreas de lazer, $43 \%$ responderam que às vezes as utilizam, ainda cabe destacar que nenhum morador respondeu utilizar sempre as áreas de lazer.

Conforme podemos perceber a partir dos números acima, os moradores de ambos os condomínios, pouco utilizam as áreas de lazer disponíveis, embora estas sejam um dos aspectos mais frisados pelos promotores imobiliários. Esta realidade pode ser explicada pelo fato de que, além de terem as áreas de lazer que o condomínio oferece, muitos moradores ainda têm as suas próprias áreas de lazer ou pode refletir ainda mais uma contradição, isto porque em itens anteriores os mesmos moradores respondem que não precisam sair do condomínio para se ter acesso ao lazer.

Este baixo uso talvez reflita também que a presença de múltiplas instalações para o lazer dentro dos condomínios sirva mais como símbolo de status do que como espaços para o lazer e para uma melhor qualidade de vida dos moradores. Fato semelhante nos é relatado por Caldeira quando analisa os condomínios fechados horizontais de São Paulo;

O pouco uso das áreas comuns (áreas de lazer) poderia também indicar que a presença de todas essas instalações - algumas delas bastante luxuosas - é mais marca de status do que uma condição necessária para uma vida cotidiana mais gratificante. Em outras palavras, essas instalações parecem ter a ver mais com ostentação do que com um novo padrão de sociabilidade entre vizinhos ou com novos conceitos de vida privada (CALDEIRA, 2000, p. 268).

Neste sentido, para a sociedade natalense a questão do status parece realmente ser um ponto importante para a escolha do local de moradia. Viver entre iguais dentro de um condomínio de luxo desperta o interesse de muitas pessoas da elite de Natal. Neste caso, a moradia tende a ser entendida como um símbolo de ostentação, uma condição necessária para os grupos sociais se afirmarem dentro da sociedade. 
Entretanto, a questão da moradia como símbolo de status social não aparece explicitamente no discurso dos condôminos, mas, é percebida implicitamente como sendo um ponto positivo que esta tipologia de moradia proporciona, tal realidade é percebida particularmente no condomínio Green Village. Neste condomínio, verificamos na pesquisa de campo, uma discriminação interna para com os moradores que tem "modestas" residências, sendo estes pressionados a melhorarem o padrão de suas casas para valorizar mais o condomínio e, assim, elevar o preço de seus imóveis, impedindo dessa forma, o acesso a "qualquer um". Este fato demonstra claramente uma tentativa de valorizar mais ainda o espaço e, em conseqüência, selecionar "melhor" os seus habitantes, fazendo-o segundo seus rendimentos econômicos, aspecto que torna o condomínio acessível somente para as "elites".

Conforme pudemos perceber ao longo deste tópico, os condomínios fechados horizontais já fazem parte da realidade da cidade de Natal, se constituindo em um novo tipo de prática socioespacial que tende a proporcionar significativas transformações no tecido urbano da cidade. Estas transformações estão relacionadas não só ao plano da configuração espacial, mas também no que diz respeito ao desenvolvimento das interações e relações entre os diversos grupos sociais.

Dessa forma, podemos dizer que a expansão desses empreendimentos estar relacionada diretamente ao processo de auto-segregação praticado pelas camadas de médio e alto poder aquisitivo que, buscando segurança, comodidade, acesso a áreas verdes dentre outras facilidades, acabam se retirando dos espaços públicos e se auto-confinando em seus "enclaves fortificados" proporcionando assim, a formação de áreas que tendem a homogeneidade social. Reitera-se neste ponto, a atuação dos agentes imobiliários, que cada vez mais exploram a idéia de que os condomínios fechados são, em muitos casos, a solução para os problemas relacionados à violência urbana.

\section{CONSIDERAÇÕES FINAIS}

O presente trabalho procurou avaliar as mudanças socioespaciais proporcionadas pela construção dos condomínios Green Village e Green Woods, objetivando desvendar ainda quais são os principais motivos que levam as classes média e alta da cidade a escolherem como local de moradia tais construções. Para tanto, apresentou-se uma discussão sobre a produção do espaço urbano e sua importância como instrumento para a compreensão da realidade social.

A produção do espaço urbano de Natal e sua crescente expansão proporcionou o surgimento de várias práticas socioespaciais, dentre elas os condomínios fechados horizontais, estes introduziram transformações no tecido urbano da cidade, assim como, alteraram consideravelmente a maneira como os grupos sociais interagem e desenvolvem as relações sociais.

A pesquisa evidenciou que os condomínios fechados horizontais são novas práticas socioespaciais que são responsáveis por produzirem diversos problemas para as cidades, estes dizem respeito principalmente à auto-segregação das populações de médio e alto poder aquisitivo e a forte tendência formação de espaços homogêneos. Outro ponto que foi revelado é a questão do status que essa tipologia de moradia concede aos seus moradores, neste sentido foi verificado que os grupos sociais procuram esses empreendimentos não só 
por causa da segurança, das áreas verdes e de suas áreas de lazer, ou seja, não apenas em busca de uma melhor qualidade de vida, mas, também à procura de status social.

Em suma, pelo o que foi exposto ao longo do trabalho podemos dizer que a produção do espaço urbano a partir dos condomínios horizontais nos revela as diferentes formas que os diversos grupos sociais se organizam na sociedade, assim como a forma como eles consomem o espaço.

Finalizamos evidenciando que não consideramos esgotadas as discussões aqui levantadas, porém, espera-se ter contribuído para uma reflexão dessa realidade socioespacial que ora se descortina no espaço urbano da capital do Rio Grande do Norte.

\section{REFERÊNCIAS BIBLIOGRÁFICAS}

CALDEIRA, Teresa Pires do Rio. Cidade de muros: Crime, segregação e cidadania em São Paulo. Tradução de Frank de Oliveira e Henrique Monteiro. 34 ed. São Paulo: Edusp, 2000. 400p.

CALIXTO, M. J. M. S. Produção, Apropriação e Consumo de Espaço Urbano: Uma leitura Geográfica de Dourados-MS. Campo Grande - MS. Ed: UFMS, 2004.

CARLOS, Ana Fani Alessandri. A (Re)produção do espaço urbano. São Paulo: Editora da Universidade de São Paulo, 1994.

CASTELLS, M. A questão urbana. Rio de janeiro: Paz e Terra, 1983.

CORRÊA, Roberto lobato. O espaço urbano. 4 ed. São Paulo: editora Ática, 2003.

COSTA, Ademir A. da. A Verticalização e as transformações do espaço urbano de

Natal- RN. Tese Doutorado Rio de Janeiro, UFRJ. PPGG, 2000.

HARVEY, D. A justiça social e a cidade. São Paulo: Hucitec, 1980.

LEFEBVRE, Henry. A Revolução Urbana. Tradução de Sergio Martins. 2 ed. Belo Horizonte: Ed. UFMG, 2004. 178p.

LOW-BEER, J. B. Renda da Terra - Algumas Noções Básicas para a compreensão do caso urbano. Espaço e Debates. São Paulo: NERU, n.8, jan./abr. 1983.

RIBEIRO, Luiz César de Queiroz. Dos cortiços aos condomínios fechados: as formas de produção da moradia na cidade do Rio de Janeiro. Rio de Janeiro: Civilização Brasileira, 1997.

SANTOS, Milton. A natureza do espaço técnica e tempo. Razão e emoção. 4 ed. São Paulo: Editora da Universidade de São Paulo, 2006.

SANTOS, Milton. Por uma nova geografia: da critica a geografia a uma geografia crítica. 6 ed. São Paulo: editora da universidade de São Paulo, 2004. (coleção Milton Santos; 2). 
SINGER, P. O uso do solo urbano na economia capitalista, In: MARICATO, E. (Org.), A produção capitalista da casa (e da cidade) no Brasil industrial. São Paulo Alfa-Ômega, 1979.

SOGAME, Maurício. Rudimentos para o exame da urbanização em sua fase crítica: uma aproximação ao conceito de segregação socioespacial. Geografes, Vitória, nº 2, 2001.

SOUZA E SILVA, Maria Floresia Pessoa de. Condomínios fechados: a produção habitacional contemporânea e auto-exclusão dos ricos no espaço urbano de Natal-RN (1995-2003). Natal. 2004. 368 p.

SOUZA, M. A. A. de. A identidade da metrópole. São Paulo: Hucitec/EDUSP, 1994.

SPOSITO. Maria Encarnação Beltrão. A urbanização da sociedade: Reflexões para um debate sobre as novas formas espaciais. In.: DAMIANI, Amélia B. CARLOS, Ana Fani A. SEABRA, Odette Carvalho de B. (Orgs). Novos Caminhos da Geografia. São Paulo: Contexto, 1999.

Um bom lugar para viver. Estilo Natal Shopping. Natal: Revista do Natal Shopping, $\mathrm{n}^{\circ}$, p.26-27, 2006.

VILLAÇA, Flavio. Espaço intra-urbano no Brasil. São Paulo: Studio Nobel: FAPESP: Lincoln Institute, 1998. 